\title{
Effect of education level and previous anaesthesia exposure on knowledge and perception about anaesthesia and anaesthesiologist: A questionnaire based observational study
}

\author{
Avinash Prakash',*, Anita Yadav², Habib Md. Reazaul Karim³, Anil Kumar Narayan ${ }^{4}, K_{\text {Kumar Aman }}^{5}$ \\ ${ }^{1,2,3}$ Assistant Professor, ${ }^{4}$ Associate Professor, 5Senior Resident, ${ }^{1,3,4,5}$ Dept. of Anaesthesiology, ${ }^{2}$ Dept. of Obstetrics \& \\ Gynaecology, ${ }^{\mathbf{1 2 , 3 , 4}}$ Andaman and Nicobar Islands Institute of Medical Sciences, Port Blair, India, ${ }^{5}$ Indira Gandhi ESI Hospital, \\ Jhilmil, Delhi, India
}

*Corresponding Author:

Email: dr.avinash04@gmail.com

Received: $18^{\text {th }}$ May, 2017

Accepted: $22^{\text {nd }}$ August, 2017

\begin{abstract}
Introduction and Aim: Anaesthesia as speciality has evolved very much but the services are yet very much under recognized. This may be partly because of low knowledge of anaesthesia and anaesthesiologists. School education level of patients may also affect this. This study was conducted to assess the patient's knowledge and perception about the role of anaesthesiologists, anaesthesia and their relationship with different educational level of patients and previous anaesthesia exposure

Materials and Methods: The present cross sectional study was conducted with 150 participants aged $\geq 15$ years of either sex posted for elective surgery. A questionnaire was used as data collection tool. Data of entire cohort as well as in different subgroups based on education level and previous exposure were calculated and compared using INSTAT software and $\mathrm{p}<0.05$ was considered significant.

Results: All the participants (56.67\% female; mean age $39.36 \pm 12.63$ years) completed the questionnaire. Their knowledge and awareness of anaesthesia and anaesthesiologists was very poor. Even patients with previous anaesthesia exposure were having poor knowledge ( 3 to $41 \%$ in different aspects). No difference in knowledge and awareness was noted with different educational level ( $\mathrm{p}>0.05$ ). Previously exposed patients had significantly more knowledge regarding 'who makes you unconscious', 'types of anaesthesia' and routes of 'general anaesthesia administration' but it failed to show difference in other aspects.

Conclusion: Knowledge about anaesthesia and anaesthesiologists are still very poor. School education has no positive impact and previous anaesthesia exposure increases the knowledge in limited aspects.
\end{abstract}

Keywords: Anesthesia and analgesia, Anesthetist, Awareness of education of patients, Risks involved, Recognition.

\section{Introduction}

Anaesthesia as a speciality has evolved from merely being a supportive specialty to one involved in wholesome and complete care of patients, not only in operation theatres (OT) but also in intensive care units (ICU) and pain clinics. ${ }^{1}$ Despite significant advances in anaesthesiology over the past century and a half by the development of new anaesthetic agents, techniques and new development in monitoring system, still there is not enough public exposure regarding the role of anaesthesiologist. ${ }^{2}$ In order to spread the public awareness about the role and training of anaesthesiologists, worldwide every year $16^{\text {th }}$ October is celebrated as World Anaesthesia Day. ${ }^{3}$ Despite this, the public image of anaesthesiologist is so poor that many even do not know that anaesthesiologist is a medically qualified physician. ${ }^{4}$

With the changing health care environment and safe anaesthesia practice, participation of the patient is very must necessary in decision making for anaesthesia services to be provided. For effective participation, patients need to be aware about anaesthesia and the anaesthesiologist. Patients' educational level is likely to play a role in having knowledge and awareness about anaesthesia as well as anaesthesiologists. Therefore, the present study was conducted to assess the patient's knowledge and perception about the role of anaesthesiologists, anaesthesia, related concerns and their relationship with different educational level of patients and previous anaesthesia exposure.

\section{Materials and Methods}

The present questionnaire based, cross sectional observational study was conducted in a tertiary care hospital situated in a remote Island of India. After obtaining ethical approval from the institute and informed consent from the participants, 150 patients posted for elective surgery who attended pre anaesthetic evaluation clinic (PAEC) were enrolled for the study during November 2016 to February 2017. Patients aged above 15 years of either sex posted for elective surgery and who could understand English, Hindi or Bengali were included in the study. The minimal age 15 years was selected arbitrarily taking the fact in to consideration that this is the approximate age of reaching Indian population at the level of high school education (if study is continued). Moreover, below this age a person is usually not expected to provide an answer to a research query independently. Patients with 
hearing problems, unable to speak and with altered mental status were excluded from the study. Patients who are working in hospital attached to OT, ICU, emergency medicine or family member of anaesthesiologists if any were also excluded. A questionnaire containing questions related to the knowledge of anaesthesia, anaesthesiologists and their concerns / perception of risk related to anaesthesia over and above socio demographic parameters were prepared and used the study tool. Each question was provided with multiple possible choices prepared by a panel of three anaesthesiologists, one gynaecologist and one lay man and was reviewed by one senior anaesthesiologist. The questionnaire was tested for two days as a pilot and acceptability among the patients was found good. Consented patients were asked to fill the questionnaire by themselves. The participants who were unable to read or understand the questions, the study investigators were available to assist the participants to clarify doubts so that they can complete the questionnaire. Patients had to select either the most appropriate option according to him / her or multiple options as per instructions. The option of 'do not know' or 'no idea' was provided with most questions. Data were then calculated for entire cohort as well as in different subgroups based on school education level (i.e. illiterate, primary, middle primary, high school, higher secondary, graduate etc) and compared higher educated levels with reference to illiterate and up to primary education level. Similarly data were sub grouped based on previous exposure to anaesthesia and compared. Qualitative data/ descriptive responses were expressed in absolute numbers and percentage scale. Mean, median, standard deviation (SD) and 95\% lower and upper limit were also calculated for quantitative data using INSTAT software (Graph Pad Prism Software, La Zolla, CA, USA). Comparisons were done using Fishers exact test and $\mathrm{p}<0.05$ was considered as significant.

\section{Result}

All the 150 participants completed the questionnaire. The participants were in between 15 to 70 years with mean \pm SD being $39.36 \pm 12.63$ years; 65 $(43.33 \%)$ participants were male. $69.33 \%$ of the participants were having above primary level school education and $45.33 \%$ were having previous exposure to anaesthesia and surgery. The distributions of socio demographic variables of the entire cohort are presented in table 1 .

Table 1: distribution of socio demographic variables of the participants. (CI - confidence interval)

\begin{tabular}{|l|c|}
\hline \multicolumn{1}{|c|}{ Parameters of N = 150 } & n (\%) / mean (95\% CI) \\
\hline Male & $65(43.33 \%)$ \\
Female & $85(56.67 \%)$ \\
\hline Age & $39.36(37.34-41.38)$ \\
Age groups & \\
$16-40$ & $60(53.33 \%)$ \\
$41-65$ & $07(44.67 \%)$ \\
$>65$ & $03(2 \%)$ \\
& \\
\hline Education level & $12(8 \%)$ \\
Illiterate & $34(22.67 \%)$ \\
Up to primary school & $23(15.33 \%)$ \\
Up to middle primary school & $33(22 \%)$ \\
Up to high school & $27(18 \%)$ \\
Up to higher secondary school & $21(14 \%)$ \\
Graduate and more & \\
\hline Residence & $43(28.67 \%)$ \\
Urban & $107(71.33 \%)$ \\
Rural & \\
\hline Occupation & $20(13.33 \%)$ \\
Student & $78(52 \%)$ \\
Housewife & $03(2 \%)$ \\
Retired & $17(11.33 \%)$ \\
Government Job & $32(21.33 \%)$ \\
Private Job & $68(45.33 \%)$ \\
\hline History of previous exposure of anaesthesia & $82(54.67 \%)$ \\
Yes & \\
No &
\end{tabular}


The entire cohort heard about the term anaesthesia and preanaesthesia evaluation either before or this time. The information regarding anaesthesia were however very poor (table 2); $31.33 \%$ were having no idea on types of anaesthesia, $21.33 \%$ and $71.33 \%$ having no idea on route of administration for GA and regional anaesthesia respectively.

Table 2: knowledge and information regarding anaesthesia among the participants

\begin{tabular}{|c|c|}
\hline Questions with options & $\mathrm{n}(\%)[\mathrm{N}=150]$ \\
\hline $\begin{array}{l}\text { The anaesthetic technique depends on the? } \\
\text { Wish and experience of the Anaesthesiologist } \\
\text { Patient's wish } \\
\text { Type of the surgical procedure } \\
\text { Patients health condition } \\
\text { Don't Know }\end{array}$ & $\begin{array}{c}06(4 \%) \\
01(0.67 \%) \\
07(4.67 \%) \\
54(36 \%) \\
82(54.67 \%) \\
\end{array}$ \\
\hline $\begin{array}{l}\text { Will follow pre-operative instructions? } \\
\text { Yes } \\
\text { No } \\
\text { Don't know }\end{array}$ & $\begin{array}{c}11(7.33 \%) \\
00 \\
139(92.67 \%)\end{array}$ \\
\hline $\begin{array}{l}\text { Importance of questions about patient previous } \\
\text { medical history or potential toxic habits? } \\
\text { To avoid liability in the event of any complications } \\
\text { arises } \\
\text { To determine the patient risk and clinical condition } \\
\text { Do not know }\end{array}$ & $\begin{array}{c}00 \\
28(18.67 \%) \\
122(81.33 \%)\end{array}$ \\
\hline $\begin{array}{l}\text { Knowledge on types of Anaesthesia } \\
\text { General } \\
\text { Regional } \\
\text { Local } \\
\text { All } \\
\text { No idea }\end{array}$ & $\begin{array}{c}64(42.67 \%) \\
09(6 \%) \\
00 \\
30(20 \%) \\
47(31.33 \%)\end{array}$ \\
\hline $\begin{array}{l}\text { Route of administration of general anaesthesia } \\
\text { With gas } \\
\text { Injection } \\
\text { Both } \\
\text { No idea }\end{array}$ & $\begin{array}{l}49(32.67 \%) \\
21(14 \%) \\
48(32 \%) \\
32(21.33 \%)\end{array}$ \\
\hline $\begin{array}{l}\text { Route of administration of regional anaesthesia } \\
\text { Administration by needle in back } \\
\text { Administer locally } \\
\text { Both } \\
\text { No idea }\end{array}$ & $\begin{array}{c}18(12 \%) \\
00 \\
25(16.67 \%) \\
107(71.33 \%) \\
\end{array}$ \\
\hline $\begin{array}{l}\text { Information source regarding anaesthetic and } \\
\text { Anaesthesiologist } \\
\text { Hear say } \\
\text { Told by other doctor } \\
\text { Read somewhere } \\
\text { Previous experience }\end{array}$ & $\begin{array}{c}54(36 \%) \\
13(8.67 \%) \\
15(10 \%) \\
68(45.33 \%)\end{array}$ \\
\hline
\end{tabular}

The knowledge regarding anaesthesiologist was also very poor; only $12 \%$ knew that unconsciousness is induced by a doctor specialized in such technique. 39 (26.0\%) participants had no idea about the areas where anaesthesiologists are involved and $24.66 \%$ did not have any idea on the role of anaesthesiologists even in operation theatre. Majority of the participants believe that monitoring, making them unconscious and taking care are done by nurses or surgeons (table 3). However, more than two third participants wanted to know about anaesthesia and anaesthesiologists. 
Table 3: knowledge and information regarding anaesthesiologists among the participants. ( ${ }^{\#}$ More than one option were allowed)

\begin{tabular}{|l|l|}
\hline \multicolumn{1}{|c|}{ Questions with options } & $\mathbf{n}(\boldsymbol{\%})[\mathbf{N}=\mathbf{1 5 0}]$ \\
\hline Who makes unconscious at time of surgery? & \\
Surgeon & $22(14.67 \%)$ \\
Surgeon assistant & $14(9.33 \%)$ \\
Doctor specialized in making unconscious & $18(12 \%)$ \\
Nurse & $66(44 \%)$ \\
Do not know & $30(20 \%)$ \\
\hline Who takes care of patient in operation theatre if any & \\
problem arises & $12(8 \%)$ \\
Anaesthesiologist & $52(34.67 \%)$ \\
Surgeon & $77(51.33 \%)$ \\
Nurse & 00 \\
Physician & $09(6 \%)$ \\
Do not know & \\
\hline Anaesthesiologists are involved in ${ }^{\#}$ & \\
Operation theatre (OT) & $46(30.66)$ \\
Intensive Care Unit ( ICU) & $40(26.66)$ \\
ICU + OT & $27(18.00)$ \\
Labor Analgesia & 00 \\
Cancer pain & 00 \\
Transfer of patients & 00 \\
No idea & $37(24.66)$ \\
\hline Role of Anaesthesiologist in operation theatre & \\
Put patient to sleep & $17(11.33)$ \\
Keep patient alive during surgery & $33(22.00)$ \\
Treat medical problem of patients & $01(0.66)$ \\
Help the Surgeon & $26(17.33)$ \\
Monitor heart, BP and breathing etc during surgery & $34(22.66)$ \\
All of the above options & $24(16.00)$ \\
Do not know & $39(26.00)$ \\
\hline Would like to know more about the work of an & $104(69.33 \%)$ \\
Anaesthesiologist? & $46(30.67 \%)$ \\
Yes & \\
No & \\
\hline & \\
\hline
\end{tabular}

The most common concern / fear to undergo anaesthesia were pain during and after anaesthesia/surgery (36\%). Eighteen participants (12\%) feared of not coming out of anaesthesia and $16 \%$ had fear of death. The perceptions of risks are shown in the pie chart (Fig. 1). None of the participants opted more than one option. 


\begin{tabular}{ll}
\hline$\square$ Needle Prick & $\square$ Pain \\
$\square$ Awareness & $\square$ Backache \\
$\square$ Not coming out of anaesthesia & $\square$ Death \\
$\square$ No idea / fear & \\
\hline
\end{tabular}

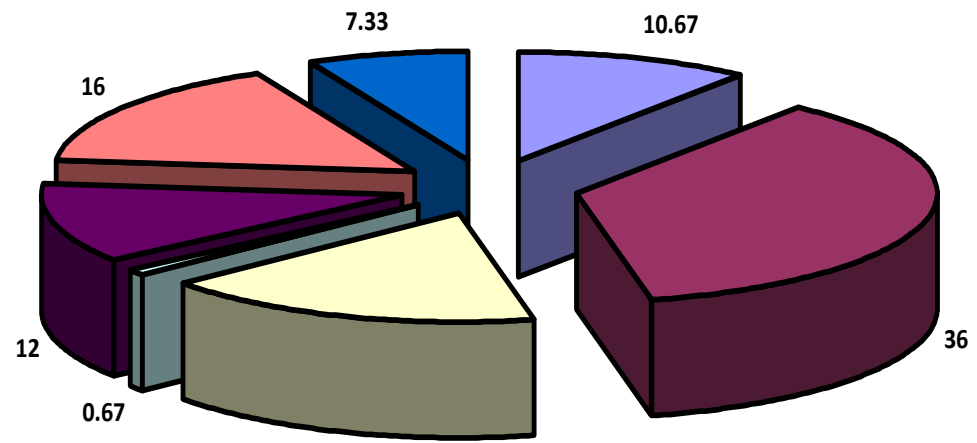

Fig. 1: perception of risk and fear of anaesthesia among the participants. (Note- more than one options were allowed)

The knowledge of anaesthesia among different education group varied between 14 to $39 \%$ in different categories however there was no difference in the knowledge level among the groups when compared with illiterate and up to primary level educated participants (table 4).

Table 4: comparison of information regarding anaesthesia among the participants with below and above primary level school education. ( $\mathrm{n}$ - number, $\mathbf{N}$ - total number, $\mathbf{R R}$ - relative risk, $\mathbf{C I}$ - confidence interval)

\begin{tabular}{|l|c|c|c|}
\hline \multicolumn{1}{|c|}{ Education based class } & n (\%) & RR (95\% CI) & P value \\
\hline a. Types of Anaesthesia & $12(26.09)$ & ---- & Reference \\
\hline Illiterate \& up to primary [N=46] & $4(17.39)$ & $0.66(0.24-1.84)$ & 0.550 \\
\hline Middle primary [N=23] & $8(24.24)$ & $0.92(0.42-2.01)$ & 1.00 \\
\hline High School [N=33] & $4(14.81)$ & $0.56(0.20-1.58)$ & 0.381 \\
\hline Higher secondary [N=27] & $2(14.81)$ & $0.36(0.08-1.48)$ & 0.195 \\
\hline Graduate and more [21] & \multicolumn{3}{|l|}{} \\
\hline b. Route of GA administration \\
\hline Illiterate \& up to primary [N=46] & $15(32.61)$ & --- & Reference \\
\hline Middle primary [N=23] & $9(39.13)$ & $1.2(0.62-2.31)$ & 0.603 \\
\hline High School [N=33] & $9(27.27)$ & $0.83(0.41-1.67)$ & 0.804 \\
\hline Higher secondary [N=27] & $9(33.33)$ & $1.02(0.51-2.01)$ & 1.00 \\
\hline Graduate and more [21] & $6(28.57)$ & $0.87(0.39-1.93)$ & 0.785 \\
\hline c. Route of RA administration & $7(15.22)$ & --- & Reference \\
\hline Illiterate \& up to primary [N=46] & $5(21.73)$ & $1.42(0.50-4.01)$ & 0.516 \\
\hline Middle primary [N=23] & $6(18.18)$ & $1.19(0.44-3.23)$ & 0.765 \\
\hline High School [N=33] & $4(14.81)$ & $0.97(0.31-3.02)$ & 1.00 \\
\hline Higher secondary [N=27] & $3(14.28)$ & $0.93(0.26-3.27)$ & 1.00 \\
\hline Graduate and more [21]
\end{tabular}

Participants with school education level of higher secondary and above were significantly more aware that anaesthesiologist makes them unconscious. However, the knowledge regarding the role and places where anaesthesiologists were involved was not statistically different or inconsistent in relation (table 5). 
Table 5: comparison of information regarding anaesthesiologists among the participants with below and above primary level education. ( $\mathrm{n}$ - number, $\mathrm{N}$ - total number, $\mathbf{R} \mathrm{R}$ - relative risk, $\mathrm{CI}$ - confidence interval).

\begin{tabular}{|l|c|c|c|}
\hline \multicolumn{1}{|c|}{ Education based class } & n (\%) & RR (95\% CI) & P value \\
\hline a. & $2(4.35)$ & & Reference \\
\hline Illiterate \& up to primary [N=46] & $1(4.35)$ & $1.00(0.09-10.46)$ & 1.00 \\
\hline Middle primary [N=23] & $4(12.12)$ & $2.78(0.54-14.34)$ & 0.229 \\
\hline High School [N=33] & $6(22.22)$ & $5.11(1.10-23.56)$ & 0.045 \\
\hline Higher secondary [N=27] & $5(23.81)$ & $5.47(1.15-25.97)$ & 0.027 \\
\hline Graduate and more [21] & $1(2.17)$ & ---- & Reference \\
\hline b. Who takes care of you during unconsciousness \\
\hline Illiterate \& up to primary [N=46] & $1(4.34)$ & $2.00(0.13-30.57)$ & 1.00 \\
\hline Middle primary [N=23] & $3(9.09)$ & $4.18(0.45-38.46)$ & 0.302 \\
\hline High School [N=33] & $4(14.81)$ & $6.81(0.80-57.9)$ & 0.059 \\
\hline Higher secondary [N=27] & $3(14.28)$ & $6.57(0.72-59.54)$ & 0.087 \\
\hline Graduate and more [21] & $14(30.43)$ & ---- & Reference \\
\hline c. & $5(21.73)$ & $0.71(0.29-1.74)$ & 0.571 \\
\hline Illiterate \& up to primary [N=46] & $2(6.06)$ & $0.19(0.04-0.81)$ & 0.009 \\
\hline Middle primary [N=23] & $4(14.81)$ & $0.48(0.17-1.32)$ & 0.167 \\
\hline High School [N=33] & $2(9.52)$ & $0.31(0.07-1.25)$ & 0.072 \\
\hline Higher secondary [N=27] & $15(32.61)$ & --- & Reference \\
\hline Graduate and more [21] & $2(8.69)$ & $0.26(0.06-1.06)$ & 0.038 \\
\hline d. Role of anaesthesiologists in OT & $10(30.30)$ & $0.92(0.47-1.80)$ & 1.00 \\
\hline Illiterate \& up to primary [N=46] & $5(18.51)$ & $0.56(0.23-1.38)$ & 0.278 \\
\hline Middle primary [N=23] & $4(19.04)$ & $0.58(0.22-1.54)$ & 0.381 \\
\hline High School [N=33] & \\
\hline Higher secondary [N=27] &
\end{tabular}

Participants with previous anaesthesia exposure were having 2 to 3 times more knowledge $(\mathrm{p}<0.05)$ on types of anaesthesia, role of anaesthesiologist in OT and places where anaesthesiologists are involved. However, they were not having more knowledge on who makes them unconscious and who takes care of them during unconsciousness (table 6).

Table 6: comparison of information regarding anaesthesia and anaesthesiologists among the participants without (Gr - A) and with (Gr- B) previous exposure of anaesthesia. ( $\mathrm{n}$ - number, $\mathbf{N}$ - total number, $\mathbf{R R}$ relative risk, $\mathrm{CI}$ - confidence interval).

\begin{tabular}{|l|c|c|c|c|}
\hline \multicolumn{1}{|c|}{ Parameters } & $\begin{array}{c}\text { Gr- A } \\
\mathbf{n}(\boldsymbol{\%})\end{array}$ & $\begin{array}{c}\text { Gr - B } \\
\mathbf{n}(\boldsymbol{\%})\end{array}$ & RR (95\% CI) & $\begin{array}{c}\text { P } \\
\text { value }\end{array}$ \\
\hline Types of Anaesthesia & $10(12.19)$ & $20(29.41)$ & $2.41(1.21-4.79)$ & 0.013 \\
\hline Route of GA administration & $20(24.39)$ & $28(41.18)$ & $1.68(1.04-2.71)$ & 0.035 \\
\hline Route of RA administration & $12(14.63)$ & $13(19.12)$ & $1.30(0.63-2.67)$ & 0.513 \\
\hline Who makes you unconscious & $15(18.29)$ & $3(4.41)$ & $0.24(0.07-0.79)$ & 0.01 \\
\hline Who takes care during unconsciousness & $10(12.19)$ & $2(2.94)$ & $0.24(0.05-1.06)$ & 0.065 \\
\hline $\begin{array}{l}\text { Places where anaesthesiologists are } \\
\text { involved }\end{array}$ & $7(8.54)$ & $20(29.41)$ & $3.44(1.55-7.65)$ & 0.001 \\
\hline Role of anaesthesiologists in OT & $13(15.85)$ & $23(33.82)$ & $2.13(1.17-3.88)$ & 0.012 \\
\hline
\end{tabular}

\section{Discussion}

The work of anaesthesiologist has crossed the boundary of operation theatre and renders services as a leader in the ICU, resuscitation, pain management, trauma care etc. With the advancement of anaesthesia even major, complex and advanced surgeries has become a reality. ${ }^{5}$ The American Society of Anaesthesiologist (ASA) has supported a strong campaign to improve the public perception and understanding of Anaesthesiologist role. ${ }^{6}$ Every year anaesthesiologist also celebrates $16^{\text {th }}$ October as world anaesthesia day. ${ }^{3}$ India is also celebrating it with a motto to give more and more knowledge and awareness to the public. Despite all these, anaesthesia is hardly known by the general population. The present study also showed that there is very less knowledge about anaesthesia as well as anaesthesiologist; only $12 \%$ of the patients correctly knew that it is the 
anaesthesiologist who makes them unconscious for the surgery. Similar results were seen in a Nigerian Study. ${ }^{7}$

Intra-operative monitoring is an important role of anaesthesiologist. However, $51.33 \%$ of patients answered that the nurses are doing this. Even the surgeon was more commonly selected than anaesthesiologists $(34.67 \%$ versus $8 \%)$. Similar results were noticed in Gottschalk et al study where patients gave less recognition of the anaesthesiologists' functions and the clear overvaluation of the surgeons. ${ }^{8}$ There could be two possible reasons for this; firstly, female anaesthesiologists (doctors) are frequently thought of as nursing staff, and secondly monitoring in general wards is done by nursing staff. In contrast the study done by Oliveira et al., $72 \%$ of their patients believed that the anaesthesiologist was responsible for the wellbeing of patient in OT. ${ }^{9}$ The commonest reason for lack of knowledge in any field is assumed to be illiteracy. But education level and exposure to anaesthesia is not or cannot be the only factor in context to our population as evidenced by the fact that $45.33 \%$ of the participants were having experience of previous surgery and anaesthesia, still only $12 \%$ had the knowledge about it. There was no statistically significant correlation $(p>0.05)$ between the knowledge about anaesthesia and anaesthesiologist with the patients education level.

Present survey showed that patient with previous experience of anaesthesia had good knowledge of anaesthesia techniques and anaesthesiologist as compared to those without previous exposure. Similar results were observed in a study by Kadri et al. and Ahmad et al. ${ }^{10,11}$ This is in contrary to a study conducted in India where previous anaesthesia experience does not influenced patients knowledge and fears about anaesthesia. ${ }^{3,12-15}$

The profession of anaesthesiology has long been suffering from low appraisal. Though many reasons can be attributed to this, one of the major reasons is that the patient first goes to a surgeon for their disease and is later referred to an anaesthesiologist. Another reason may be that they usually do not meet the anaesthesiologist when being admitted in the hospital.

There is a considerable confusion in the public mind about what the anaesthesiologists actually do during the surgery and what their other responsibilities are. In the survey by Eyelade et al., $48 \%$ of patients had no idea about anaesthesiologist role in OT, while $24 \%$ listed putting patients to sleep; monitoring vitals and offering pain relief. ${ }^{7}$ The present study findings were also more or less similar to them. The knowledge of the patients regarding job of the anaesthesiologist outside the operation theatre were also not encouraging. Despite the fact that most of the ICUs in India is managed by anaesthesiologists, none of our patients were aware about importance of anaesthesiologists in specialized intravenous access, resuscitation, labor analgesia, ICU care etc. These results were consistent with the findings of Kadri et al. study. ${ }^{10}$

The reasons of such low level of knowledge and awareness are that anaesthesiologists spend very minimal time with the patients before surgery. Even the anaesthesiologists who do PAEC and the ones who actually perform anaesthesia are different, most of the times in medical colleges and institutions. There is a huge communication gap between anaesthesiologists and patients. Many a time anaesthesiologists even do not introduce themselves, do not explain the procedure properly and even do not take separate consent. Irrespective of the level of education or knowledge, there is a huge (i.e. 69.33\%) desire among the public to know about anaesthesia and anaesthesiologist. So the findings of having very poor knowledge in previously exposed patients clearly indicate that anaesthesiologist takes very casual approach in communication and providing information to the patients.

The importance and effectiveness of print and electronic media can never be overlooked among the general public. Anaesthesiologists also hardly spare time to write articles for the local news-papers, give interviews for local TV channels, etc. So, only celebrating world anaesthesia day is not helping anaesthesiologist much in getting their due recognition. Each patient coming for anaesthesiologist services and not being educated by attending anaesthesiologist would be a missed opportunity to spread awareness regarding anaesthesiology. Therefore, it is of paramount importance that anaesthesiologists take the responsibility to give information about anaesthesia, possible complications and obtain separate anaesthesia consent. In present study, $42 \%$ of patients were aware about GA. This finding was in accordance with the study by Kadri et al. and Ahamad et al. ${ }^{10,11}$ However, only $6 \%$ of patients were aware about regional anaesthesia whereas presently a major share of the cases are being conducted under regional anaesthesia.

Indian community is a close knit one where hearsay amongst the social framework and sharing of personal experiences with other people, is perhaps more important than formal education. The finding of the present study has also proven this. Taking into this observation in account, the best source to educate society regarding role of anaesthesiologists in patient care would be direct interaction with the patients, involving discussions, lectures, video presentations or demonstrations.

The present study however is having relatively lower sample and power. The study was also done in a single centre. Although the present study has these limitations, it gives a strong wake up call for anaesthesiologists to change their practice pattern and approach to the patients. 


\section{Conclusion}

The present questionnaire based survey among preoperative patients showed that the knowledge about anaesthesia and anaesthesiologists are very poor among public. Patients are even not aware about the risks they are taking. School education has no impact in achieving such knowledge and awareness. Even previous anaesthesia exposure increases the knowledge/awareness in limited aspects. Anaesthesiologists should spend more time with patients explaining the managements, anaesthesia procedures, risks; should take separate consent and visit patients in postoperative period regularly

\section{References}

1. Singla D, Mangla M. Patient's Knowledge and perception of preanesthesia check - up in rural India. Anesth Essays Res 2015;9:331-6. doi:10.4103/0259-1162.158008

2. Acosta-Martinez J, Guerrero-Rodriguez R, LopezHerrera-Rodriguez D, Sanchez- Carrilo F. The anaesthetist's role from the patient's perspective. Rev Colomb Anestesiol 2016;44:121-7.

3. Prasad CGS, Suresh G. A survey on public awareness about the role of anaesthesiologists. Ain-Shams J Anesthesiol 2014;7:456-9.

4. Erden A, Tutuncu R. Patients' knowledge and attitudes about the role of anesthesiologists in a military Hospital. $\mathrm{J}$ Clin Exp Invest 2012;3:313-7. doi:10.5799/ahinjs.01.2012.03.0170

5. Naod B, Admasu W, Ahmed Y. Patients' Knowledge and Attitude towards Anesthesia in Tikur Anbesa Specialized Hospital. Int J Anesth Res 2016;4:229-35. doi:10.19070/2332-2780-1600052

6. Leite F, Silva LM, Biancolin SE, Dias A, Castiglia YMM. Patient perceptions about anesthesia and anesthesiologists before and after surgical procedures. Sao Paulo Med J 2011;129:224-9.

7. Eyelade OR, Akinyemi JO, Adewole IF. Patients' perception and knowledge of anesthesia and anesthetistsa questionnaire survey. S Afr J Anaesthesiol Analg 2010;16:28-31. doi:10.1080/22201173.2010.10872695

8. Gottschalk A, Seelen S, Tivey S, Gottschalk A, Rich G. What do patients know about anesthesiologists? Results of a comparative survey in an U.S., Australian, and German university hospital. J Clin Anesth 2013;25:85-91. doi:10.1016/j.jclinane2012.06.017

9. Oliveira KF, Clivatti J, Munechika M, Falcao LFR. What do patients know about the work of Anesthesiologists? Rev Bras Anestesiol 2011;61:720-7.

10. Kadri IA, Haider G, Memon I, Memon W. Awareness of patients regarding anesthesia; attitude towards basic types of anesthesia techniques. Professional Med J 2014;21:782-7.

11. Ahamad I, Afshan G. Knowledge and attitudes of Pakistani women towards anaesthesia techniques for Caesarean section. J Pak Med Assoc 2011;61:359-62.

12. Naithani U, Purohit D, Bajaj P. Public awareness about anaesthesia and anaesthesiologist: A survey. Indian J Anaesth 2007;51:420-6.

13. Marulasiddappa V, Nethra HN. A Survey on Awareness about the Role of Anesthesia and Anesthesiologists among the Patients Undergoing Surgeries in a Tertiary Care Teaching Women and Children Hospital. Anesth Essays Res 2017;11:144-50. doi:10.4103/02591162.186595
14. Uma BR, Hanji AS. "Anaesthesia and Anaesthesiologists: How Famous are We among the General Population?" A Survey. J Clin Diagn Res 2013;7:2898-900. doi: $10.7860 / J C D R / 2013 / 7084.3788$

15. Mathur SK, Dube SK, Jain S. Knowledge about anaesthesia and anaesthesiologist amongst general population in India. Indian J Anaesth 2009;53:179-86. 